Editorial

\title{
Introduction to the Special Issue on Human-Computer Interaction and the Social Web
}

\author{
Salvatore Carta and Ludovico Boratto * \\ Dipartimento di Matematica e Informatica, Università di Cagliari - Via Ospedale 72, 09124 Cagliari, Italy; \\ salvatore@unica.it \\ * Correspondence: ludovico.boratto@acm.org; Tel.: +39-0706758755 \\ Academic Editor: Dino Giuli
}

Received: 22 August 2016; Accepted: 25 August 2016; Published: 1 September 2016

In recent years, both Human-Computer Interaction (HCI) and the Social Web (also known as Web 2.0) have had exponential growth.

In [1], Human-Computer Interaction is defined as "a discipline concerned with the design, evaluation, and implementation of interactive computing systems for human use and with the study of major phenomena surrounding them". On the other hand, [2] defines the Social Web as "a set of relationships that link together people over the Web ... The Social Web is not just about relationships, but about the applications and innovations that can be built on top of these relationships".

As the two definitions quoted above suggest, the two disciplines can work well together. In fact, an HCI application could be developed in the Social Web scenario, in order to study and improve relationships among people. Moreover, Turekten and Olfman highlighted that the 'any time, any place' nature of HCI has not been widely explored in the Web 2.0 research area [3].

This special issue includes four papers that explore (and try to cover) this gap between HCI and the Social Web.

In the first paper, Golbeck and Mauriello [4] study the perception that the users had on the personal data they disclosed while using Facebook apps. The study shows that users are very concerned about data privacy, but they are not aware of the personal data an application can access. After gathering more information on the data an app can access, the concerns about the privacy issues are increased. However, even after getting explicit information, some of the participants of the study still could not understand which types of data an app could access.

In the second paper, Massa and Spano [5] propose FaceMashup, a tool that allows users to create procedures to inspect and control their data. The different data types in the Facebook Graph API (e.g., user profiles, photos, etc.) are represented through widgets that contain user interface elements. A user can drag and connect these widgets to retrieve, combine, and filter data coming from the Facebook graph. Moreover, she can perform actions on the selected entries through a set of action widgets.

In the third paper, Golbeck and Neustaedter [6] explore the environmental factors that lead people to participate in outdoor leisure activities. In particular, they focus on Geocache, a social web-based treasure hunt game, in which players hide physical containers for other players to find using GPS coordinates posted online. A preliminary analysis on data collected from OpenCaching.com in the US and Canada showed that geocaches were more often found in areas that were wealthier, better educated, younger, and more urban, and had higher population density and better weather. A survey conducted on twenty geocachers showed that those who cache think carefully about where they do their activities, in order to minimize the risks, while cache seekers think less about these concerns.

In the last paper, Ibba and Pani [7] propose a novel metadata taxonomy, built through the analysis and the integration of existing metadata schemas associated with digital libraries and through the interpretation and the combining of Instagram metadata and Instagram hashtags. 
The final taxonomy provides innovative metadata with respect to the classification of resources, as images of Instagram and user-generated content.

Acknowledgments: This work is partially funded by Regione Sardegna under project NOMAD (Next generation Open Mobile Apps Development), through PIA-Pacchetti Integrati di Agevolazione "Industria Artigianato e Servizi" (annualità 2013).

Author Contributions: S.C. and L.B. wrote the paper.

Conflicts of Interest: The authors declare no conflict of interest.

\section{References}

1. Hewett, T.T.; Baecker, R.; Card, S.; Carey, T.; Gasen, J.; Mantei, M.; Perlman, G.; Strong, G.; Verplank, W. ACM SIGCHI Curricula for Human-Computer Interaction; ACM SIGCHI: New York, NY, USA, 1996.

2. Appelquist, D.; Brickley, D.; Carvahlo, M.; Iannella, R.; Passant, A.; Perey, C.; Story, H. A Standards-Based, Open and Privacy-Aware Social Web; World Wide Web Consortium (W3C): Cambridge, MA, USA, 2010.

3. Turetken, O.; Olfman, L. Introduction to the Special Issue on Human-Computer Interaction in the Web 2.0 Era. AIS Trans. Hum.-Comput. Interact. 2013, 5, 1-5.

4. Golbeck, J.; Mauriello, M.L. User Perception of Facebook App Data Access: A Comparison of Methods and Privacy Concerns. Future Internet 2016, 8, 9.

5. Massa, D.; Spano, L.D. FaceMashup: An End-User Development Tool for Social Network Data. Future Internet 2016, 8, 10.

6. Golbeck, J.; Neustaedter, C. Environmental Factors Affecting Where People Geocache. Future Internet 2016, 8, 11 .

7. Ibba, S.; Pani, F.E. Digital Libraries: The Challenge of Integrating Instagram with a Taxonomy for Content Management. Future Internet 2016, 8, 16.

(c) 2016 by the authors; licensee MDPI, Basel, Switzerland. This article is an open access article distributed under the terms and conditions of the Creative Commons Attribution (CC-BY) license (http://creativecommons.org/licenses/by/4.0/). 